\title{
Adherence to type 2 diabetes management
}

\author{
NITISHA KHUNTI, ${ }^{1}$ NEHAL KHUNTI, ${ }^{2}$ KAMLESH KHUNTI ${ }^{3}$
}

\begin{abstract}
Tight glycaemic control is essential, and good adherence is associated with a lower risk of all-cause mortality and hospitalisation in people with T2D. A significant number of people with T2D do not take medication as prescribed and therefore have poor outcomes. The key factors for not achieving targets include therapeutic inertia and adherence. Reasons for poor adherence include perception of treatment, complexity of treatment and adverse effects. Poor adherence leads to inadequate glycaemic control, which increases the risk of diabetic complications and mortality. There is evidence to suggest that education and monitoring is important in medication adherence.
\end{abstract}

Br J Diabetes 2019;19:99-104

Key words: type 2 diabetes, poor adherence, glycaemic targets, lifestyle changes, glucose-lowering drugs

\section{Introduction}

Diabetes is a chronic disease affecting 463 million people worldwide in 2018 and has been reported to be in the top 10 causes of death globally. ${ }^{1}$ In the financial year 2018/2019 there were 55 million items prescribed for diabetes, with a total net cost of over f1 billion. ${ }^{2}$ Type 2 diabetes (T2D) is a progressive disease with loss of beta-cell function and insulin resistance leading to a failure of glycaemic control. ${ }^{3}$ In the UK the National Institute for Health and Care Excellence (NICE) advises glycated haemoglobin ( $\left.\mathrm{HbA}_{1 c}\right)$ targets of $<6.5 \%(<47.5 \mathrm{mmol} / \mathrm{mol})$ in newly diagnosed patients and $<7.5 \%(<58 \mathrm{mmol} / \mathrm{mol})$ in patients on two or more therapies. NICE suggests reaching these targets by use of glucose-lowering drugs (GLDs), management of other risk factors such as blood pressure and lipids and lifestyle changes. However, they also recommend relaxing target $\mathrm{HbA}_{1 \mathrm{c}}$ levels in certain individuals, such as those who are frail, those who are at risk of hypoglycaemic events which could lead to high-risk consequences and those

University of Nottingham, Queen's Medical Centre, Nottingham, UK

2 County Pharmacy, 14 Stretton Court, Stretton Road, Great Glen, Leicester, UK

3 Diabetes Research Centre, University of Leicester, Leicester General Hospital, Leicester, UK

Address for correspondence: Dr Nitisha Khunti University Hospital Coventry and Warwickshire, Clifford Bridge Road, Coventry, CV2 2DX, UK

E-mail: tish_404@hotmail.com

https://doi.org/10.15277/bjd.2019.223

\begin{tabular}{ll} 
Table 1 & Key definitions \\
\hline Adherence & $\begin{array}{l}\text { The extent to which a person's behaviour (taking } \\
\text { medication, following a diet, and/or executing lifestyle } \\
\text { changes) corresponds with agreed recommendations } \\
\text { from a healthcare provider }\end{array}$ \\
Concordance & $\begin{array}{l}\text { Joint agreement between the prescriber and the } \\
\text { patient regarding therapeutic decisions, including } \\
\text { using prescribed medication in a given way }\end{array}$ \\
Compliance & $\begin{array}{l}\text { The extent to which the patient's behaviour matches } \\
\text { the prescriber's recommendations }\end{array}$ \\
Persistence & The duration of medication use by the patient ${ }^{10}$
\end{tabular}

unlikely to achieve longer term risk reduction benefits. ${ }^{4}$

Many people are unable to control their T2D solely by lifestyle changes and will therefore ultimately need multiple GLDs including insulin. ${ }^{5}$ Controlling glycaemia is essential, and good adherence is associated with a lower risk of all-cause mortality and hospitalisation in people with T2D. ${ }^{6}$ However, a significant number of people with T2D still do not take medication as prescribed and therefore have poor outcomes. ${ }^{7}$ The key factors for not achieving targets include therapeutic inertia and adherence. ${ }^{8}$ In this narrative review we discuss the prevalence, consequences and interventions to overcome non-adherence.

\section{Definitions of adherence, concordance, compliance and persistence}

A number of terms are often used interchangeably to describe a patient's medication-taking behaviour including adherence, concordance, compliance and persistence (see Table 1). However, use of the term 'compliance' is declining as it suggests lack of patient involvement.

\section{Adherence to T2D management}

The World Health Organization stated that, in developed countries, adherence to medication in chronic conditions is only around $50 \%$. Decreased levels of adherence are normally seen in patients with chronic conditions compared with those with acute conditions, and this leads to poorer health outcomes and also has a substantial impact on healthcare costs. 5,13

The management of T2D firstly comprises lifestyle changes such as a decrease in calorie intake, increase in physical activity and weight loss followed by use of GLDs. Monotherapy with metformin is indicated for most patients, with the addition of further GLDs if the individualised glycaemic treatment goal is not achieved within 
3 months of metformin plus lifestyle interventions. ${ }^{14}$

The American Diabetes Association (ADA) and the European Association for the Study of Diabetes (EASD) Consensus Report recognises the significance of diet and exercise throughout all stages of T2D. ${ }^{14}$ There is strong evidence for the advantages of exercise; however, Praet and van Loon ${ }^{15}$ found that adherence to long-term exercise programmes still varies between $10 \%$ and $80 \%$. They suggest adherence may improve if exercise interventions include motivational strategies as well as taking account of time constraints and providing patients with feedback on physical activity levels.

The prevalence of non-adherence to GLDs differs greatly in studies. Cramer ${ }^{7}$ carried out a retrospective analysis, which showed adherence to oral hypoglycaemic agents (OHAs) varied between $36 \%$ and $93 \%$ in patients who continued on treatment for $6-24$ months. Rozenfeld et a ${ }^{1 / 6}$ found an inverse relationship between taking a prescribed $\mathrm{OHA}$ and the $\mathrm{HbA}_{1 \mathrm{c}}$ level. This study also showed that each $10 \%$ increase in adherence to OHA was correlated with a decrease of $0.1 \%$ in $\mathrm{HbA}_{1}$. They also concluded that, of 2,741 patients with T2D who had recently commenced OHA treatment, general adherence was $81 \%$ and $65 \%$ had good adherence (defined as $\geq 80 \%$ of medication). In another study of electronic records for a range of OHAs in 8,191 patients, $53 \%$ of whom had a $\mathrm{HbA}_{1 \mathrm{c}}$ of $\geq 7 \%(53 \mathrm{mmol} / \mathrm{mol})$, only $39.6 \%$ had persisted with treatment after 24 months. ${ }^{17}$ An additional study assessing self-reported compliance of 11,896 patients taking one or two OHAs observed that only $46 \%$ had ideal compliance. ${ }^{18}$

People with T2D commonly have multimorbidities. A number of individual studies have shown adherence to be poorer amongst patients with multimorbidities and those on polypharmacy or twicedaily therapies compared with monotherapies and once-daily regimens, respectively. ${ }^{19-21}$ Cramer's retrospective analysis also showed adherence to insulin treatment among patients with T2D was $62-64 \% .{ }^{7}$ A study of 1,099 people reported that the average adherence to insulin treatment was $71 \%$ and showed that good adherence was associated with better glycaemic control. ${ }^{22}$ Another study found that, from a sample of 144 adults, 59\% forgot to take their insulin and $46 \%$ reported non-adherence. ${ }^{17}$ The French population-based ENTRED study of 3,637 patients with T2D using both OHAs and insulin showed that $39 \%$ of patients reported good medication adherence, $49 \%$ medium adherence and $12 \%$ poor adherence. ${ }^{23} \mathrm{~A}$ systematic review of adherence to pen device insulin therapy found that adherence to vials and syringes varied from $13 \%$ to $90 \%$ and from $22 \%$ to $92 \%$, respectively. ${ }^{24}$

These studies show that there is a need for a coordinated approach to helping patients understand the disease process and encouraging concordance with management plans. Therapeutic inertia, however, also needs to be acknowledged by healthcare professionals and a structured plan must be implemented. The ADA standards of care have an algorithm for add-on medications following the initiation of metformin along with guidelines recommending $\mathrm{HbA}_{1 \mathrm{c}}$ reviews 3-6 months after commencement of further GLDs..$^{25}$ They also state that glycaemic control should then be monitored 3-6-monthly thereafter. The ADA-EASD Consensus Report released in 2018 has also outlined a general approach to
Table 2 Common reasons for poor adherence to glucose-lowering drugs

\begin{tabular}{|ll}
\hline Perception of treatment & $\begin{array}{l}\text { Misunderstanding treatment benefits } \\
\text { Fear of treatment side effects }\end{array}$ \\
Complexity of treatment & $\begin{array}{l}\text { Polypharmacy } \\
\text { Dosing frequency }\end{array}$ \\
Adverse effects & $\begin{array}{l}\text { Hypoglycaemia } \\
\text { Gastrointestinal side effects } \\
\text { Weight gain }\end{array}$ \\
\hline Insulin-specific & $\begin{array}{l}\text { Inability to regulate dosing } \\
\text { Time consumption } \\
\text { Impact on social life } \\
\text { Pain at injection site } \\
\text { Trypanophobia (fear of needles) }\end{array}$ \\
\hline
\end{tabular}

GLDs for patients with T2D and the need to reassess treatment regularly to avoid therapeutic inertia. ${ }^{14}$

Factors contributing to poor adherence to T2D treatment Despite evidence and recommendations, guidelines are not translated into practice. One study showed that, in the UK, one-third of patients with $\mathrm{T} 2 \mathrm{D}$ fail to achieve $\mathrm{HbA}_{1 \mathrm{c}}$ levels $\leq 7.5 \%$ (58 $\mathrm{mmol} / \mathrm{mol}){ }^{26}$ There are a number of possible explanations as to why patients do not always take their medication as prescribed, and often more than one factor contributes to lack of adherence. Some of these reasons cannot be changed, while others are often modifiable. ${ }^{5}$ Common reasons for poor adherence to GLDs are shown in Table 2.

Patient adherence to treatment is more likely to improve if they are able to understand that their regimen is having a positive and relative immediate influence on their outcome. ${ }^{17} \mathrm{~A}$ systematic review of a wide range of chronic diseases found that medication adherence is correlated with perceived need and that patients are more likely to be adherent, the more they believe the prescribed medication is actually required. ${ }^{27}$ Another study showed that, in patients with T2D, 32.8\% felt medication would lead to unwanted side effects and $13.9 \%$ felt it may cause weight gain, attributing to decreased adherence. ${ }^{28}$ In patients with newly prescribed insulin, $35 \%$ were found to be non-adherent with their regime. ${ }^{29}$ Reasons for this included feeling that insulin would lead to harm, concerns regarding their inability to regulate the dosing of insulin, the impact on their social life and work, the pain of the injection, side effects and that the advantages and disadvantages of insulin had not been sufficiently clarified. In one study of people with T2D and type 1 diabetes, reasons for non-adherence to insulin included reactions at injection sites, fear of hypoglycaemia, time consumption, interference with physical activity and lack of instructions. ${ }^{30} \mathrm{~A}$ qualitative meta-synthesis of the different perspectives of medication nonadherence between patients and healthcare professionals found that medication administration is a significant barrier to adherence. ${ }^{31}$ The authors stated that patients predominantly had trypanophobia (fear of needles), fear of the effects of inaccurately administering insulin and fear of the pain of injection or blood testing. 
Treatment for T2D is life long and often the complexity of the different therapies increases over time. A systematic review of 51 studies of dosing frequency and medication adherence in chronic diseases including diabetes found that medication adherence was poor with increasing daily frequency of medication: compared with once-daily dosing, the differences for twice-daily, three times daily and four times daily dosing were $-6.7 \%,-13.5 \%$ and $-19.2 \%$, respectively. ${ }^{23}$ Treatment for diabetes and its complications can include multiple tablets with daily dosing and the increasing complexity has an obvious effect on treatment adherence. In their systematic review of 76 studies Claxton et $a^{\beta 2}$ found that the frequency of dosing was inversely related to medication adherence. Adherence was significantly higher for once-daily dosing (79\%) than for three times daily dosing $(65 \%, p<0.008)$, for once-daily dosing than for four times daily dosing $(51 \% ; p<0.001)$ and for twice-daily dosing (69\%) than for four times daily dosing $(p<0.001)$. A retrospective evaluation divided their patients into low, medium and high complexity groups. ${ }^{33}$ They found that the mean one-year adherence was 58\%, 51\% and 43\%, respectively, concluding that treatment complexity has a negative impact on adherence and glycaemic control.

In a study of 2,074 patients with T2D who took more than one OHA (without insulin), 71.7\% reported at least one adverse effect such as hypoglycaemia, constipation, diarrhoea, headache or weight gain in the 2 weeks prior to questioning, leading to an increased chance of lack of adherence $(p<0.01) .{ }^{33}$ Each further adverse effect was correlated with a $28 \%$ greater likelihood of treatment non-adherence. Hauber et $a^{\beta 4}$ found that, in patients with T2D, increased weight gain and cardiovascular risk due to treatment were associated with an increased probability of non-adherence. Walz et $a^{\beta 5}$ found that, of 430 patients with T2D treated with metformin and a sulfonylurea, 34\% exhibited some form of hypoglycaemia and 19\% had moderate or severe hypoglycaemia. Despite the decreased $\mathrm{HbA}_{1 c}$ levels, this was associated with poor adherence and reduced treatment satisfaction. In another database study of 212,061 patients with T2D, low adherence was associated with hypoglycaemic events. ${ }^{36}$ Insulin was associated with the highest risk of hypoglycaemia, followed by sulfonylureas and other OHAs (eg, meglitinide and $\alpha$-glucosidase inhibitors). Thiazolidinediones, metformin and dipeptidyl peptidase-4 (DPP-4) had a low risk of hypoglycaemia. In one systematic review and a meta-analysis, adherence to metformin was lower than to sulfonylureas and thiazolidinediones and adherence to DPP-4 inhibitors was higher than to sulfonylureas and thiazolidinediones. ${ }^{37}$ The authors attributed this to the fact that metformin requires multiple daily dosing and commonly causes gastrointestinal disturbances whereas DPP-4 inhibitors are usually well tolerated. In a retrospective observational study, McGovern et al concluded that longer medication persistence was associated with improved glycaemic control; however, this differed considerably between drug classes with only metformin, sulfonylureas and sodium-glucose co-transporter-2 (SGLT-2) inhibitors having $>50 \%$ persistence at 2 years. ${ }^{38}$ Other than SGLT-2 inhibitors, metformin had the longest median persistence. Only a short follow-up duration was avail- able for SGLT-2 inhibitors, but they displayed potential for good persistence.

\section{Consequences of poor adherence}

Poor adherence leads to inadequate glycaemic control, which in turn increases the risk of diabetic complications and mortality. In a retrospective cohort study of 11,532 patients, Ho et a ${ }^{\beta 9}$ showed that medication non-adherence to OHAs, antihypertensives and statins was associated with higher $\mathrm{HbA1c}$, blood pressure and lowdensity lipoprotein cholesterol levels. In multivariable analysis, medication non-adherence was associated with an increased risk of all-cause hospitalisation (OR $1.58,95 \% \mathrm{Cl} 1.38$ to $1.81 ; \mathrm{p}<0.001)$ and higher all-cause mortality (OR 1.81, 95\% Cl 1.46 to 2.33).

One recent meta-analysis explored the association between adherence to T2D medication and the risk of cardiovascular disease, all-cause mortality and hospitalisation. ${ }^{6}$ Eight observational studies were included ( $n=318,125$ patients). The mean rate of poor adherence was $37.8 \%$. The study showed that good medication adherence $(\geq 80 \%)$ compared with poor adherence was associated with a $38 \%$ reduction in all-cause mortality (RR $0.72,95 \% \mathrm{Cl} 0.62$ to 0.82 ) and a $10 \%$ reduction in hospitalisation (RR $0.90,95 \% \mathrm{Cl} 0.87$ to 0.94$)$.

Curtis et a ${ }^{140}$ assessed the association of adherence to GLDs and the resulting outcomes in patients with T2D. They found that acute care costs and outpatient costs were significantly lower for adherent patients. Adherence was also associated with significant improvements in acute care outcomes as measured by the probability of a hospitalisation ( $17.65 \%$ vs $22.71 \%$; $p<0.0001)$, the probability of an emergency department visit ( $38.47 \%$ vs $45.61 \% ; p<0.0001$ ), the number of hospitalisations ( 0.27 vs $0.40 ; p<0.0001)$, the number of emergency department visits ( 0.83 vs $1.23 ; p<0.0001)$ and the length of stay in hospital ( 1.25 vs 2.16 days; $p<0.0001)$.

\section{Interventions to improve adherence}

The World Health Organization has stated that "increasing the effectiveness of adherence interventions may have a far greater impact on the health of the population than any improvement in specific medical treatments". ${ }^{12}$ Overall, there are a number of factors that are key to medication adherence. Table 3 summarises a number of studies including systematic reviews of interventions to improve medication adherence in people with T2D. There is evidence to suggest that education and monitoring is important in medication adherence, with pharmacist-based interactions being successful in improving glycaemic control. Monitoring via messaging and digital interventions including mobile applications have also proved effective. Currently these are costly; however, if they are able to improve long-term outcomes, they may prove to be cost effective for patients with difficulties managing their condition. ${ }^{41}$ Psychological support for patients may also be necessary to reduce fears and anxiety in those who are not adhering to management plans or for those who require additional support with their condition. ${ }^{42}$

\section{Conclusion}

$\mathrm{T} 2 \mathrm{D}$ is a progressive disease and, along with diet and exercise, phar- 
Table 3 Summary of interventions to improve adherence from 2012 to 2018

\begin{tabular}{|c|c|c|}
\hline Author & Year & Key findings \\
\hline $\begin{array}{l}\text { Omran et a/43 } \\
\text { (8 studies) }\end{array}$ & 2012 & $\begin{array}{l}\text { Pharmacist interventions to improve } \\
\text { medication adherence in diabetes } \\
\text { largely use an educational component } \\
\text { together with behavioural, affective or } \\
\text { provider-targeted strategies. These } \\
\text { interventions appear to improve } \\
\text { adherence. }\end{array}$ \\
\hline $\begin{array}{l}\text { Schoenthaler } \\
\text { and Cuffee }{ }^{44} \\
\text { (18 studies) }\end{array}$ & 2013 & $\begin{array}{l}\text { The authors concluded that medication } \\
\text { adherence could be improved when } \\
\text { practitioners are supported by skilled } \\
\text { ancillary staff who have the time to } \\
\text { provide individual patient-centred } \\
\text { adherence counselling. They also found } \\
\text { that technology can be successful and } \\
\text { economical in enhancing medication } \\
\text { adherence by providing patients with } \\
\text { continuous monitoring, feedback and } \\
\text { reinforcement. }\end{array}$ \\
\hline $\begin{array}{l}\text { Williams et a/45 } \\
\text { ( } 27 \text { studies) }\end{array}$ & 2014 & $\begin{array}{l}\text { Education, skills training and problem } \\
\text { solving are the key components of } \\
\text { intervention. One-on-one counselling } \\
\text { was found to be effective, along with } \\
\text { interventions led by other healthcare } \\
\text { professionals, with pharmacists having } \\
\text { more statistically significant results. }\end{array}$ \\
\hline $\begin{array}{l}\text { Sapkota et al }{ }^{46} \\
\text { (52 studies) }\end{array}$ & 2015 & $\begin{array}{l}\text { A large number of the interventions } \\
\text { acknowledged in the review were } \\
\text { unable to display a positive effect on } \\
\text { medication adherence. There were a } \\
\text { small number of effective interventions, } \\
\text { however similar interventions in other } \\
\text { studies were reported to be } \\
\text { unsuccessful. It was difficult for the } \\
\text { authors to conclude which interventions } \\
\text { would be the most successful. }\end{array}$ \\
\hline $\begin{array}{l}\text { Farmer et a/47 } \\
\text { (11 studies) }\end{array}$ & 2016 & $\begin{array}{l}\text { While interventions centred around } \\
\text { messaging and monitoring have the } \\
\text { potential to improve adherence to } \\
\text { therapies, the evidence is limited and } \\
\text { additional research is needed. }\end{array}$ \\
\hline $\begin{array}{l}\text { Van Eikenhorst et a/ }{ }^{48} \\
\text { ( } 24 \text { studies) }\end{array}$ & 2017 & $\begin{array}{l}\text { Pharmacist-led self-management } \\
\text { interventions significantly improved } \\
\mathrm{HbA}_{1 \mathrm{c}} \text { levels in diabetics and illustrated } \\
\text { the value of pharmacists in patient- } \\
\text { related care. }\end{array}$ \\
\hline $\begin{array}{l}\text { Jeong et } a /{ }^{49} \\
\text { (37 studies) }\end{array}$ & 2018 & $\begin{array}{l}\text { Pharmacist-led care was effective in } \\
\text { improving } \mathrm{HbA}_{1 c} \text { in diabetics with only } \\
\text { intervention periods longer than } 6 \\
\text { months having a significant impact on } \\
\text { adherence. }\end{array}$ \\
\hline $\begin{array}{l}\text { Kebede et } a^{50} \\
\text { ( } 21 \text { studies) }\end{array}$ & 2018 & $\begin{array}{l}\text { Digital interventions including the use of } \\
\text { phone applications were found to be } \\
\text { effective in reducing } \mathrm{HbA}_{1 \mathrm{c}} \text { levels in } \\
\text { patients with poorly controlled type } 2 \\
\text { diabete. }\end{array}$ \\
\hline
\end{tabular}

\section{Key messages}

- Decreased levels of adherence are often seen in patients with chronic conditions particularly those with multimorbidity leading to poor health outcomes and increased healthcare costs

- Poor adherence in T2DM is associated with increased complications \& mortality

- Patient education and monitoring improves outcomes

macological therapies are needed to sustain glycaemic control and reduce complications. However, non-adherence is common and can lead to adverse outcomes. There are a number of factors that contribute to lack of adherence such as misperception of treatment benefits, complexity of treatment and adverse effects. It is therefore evident that healthcare professionals may need to focus on improvement of adherence prior to considering additional therapies, particularly in the current climate of cost-effective prescribing. A number of interventions have been tested to improve adherence. Future studies should include targeted multifactorial interventions to improve individualised glycaemic targets with the aim of improving long-term outcomes.

Conflict of interest KK has acted as a consultant and speaker for Amgen, Astrazeneca, Bayer, NAPP, Lilly, Merck Sharp \& Dohme, Novartis, Novo Nordisk, Roche, Berlin-Chemie AG/Menarini Group, Boehringer Ingelheim, Sanofi-Aventis and Servier. Professor Khunti has received grants in support of investigator and investigator initiated trials from AstraZeneca, Novartis, Novo Nordisk, Sanofi-Aventis, Lilly, Servier, Pfizer, Boehringer Ingelheim and Merck Sharp \& Dohme.

Acknowledgements The research was supported by the NIHR Collaboration for Leadership in Applied Health Research and Care East Midlands (CLAHRC EM), NIHR Leicester, Biomedical Research Centre. The views expressed are those of the authors and not necessarily those of the NHS, the NIHR or the Department of Health and Social Care.

\section{Funding None.}

\section{References}

1. International Diabetes Federation. International Diabetes Federation Diabetes Atlas. 9th edition. Brussels, Belgium: International Diabetes Federation. 2019. Available from: http://www. diabetesatlas.org.

2. NHS Digital. Prescribing for Diabetes in England: 2008/09-2018/19. 2019. Available from: https://digital.nhs.uk/data-and-information/publications/statistical/prescribing-for-diabetes/2008-09---2018-19.

3. Fonseca V. Defining and characterizing the progression of type 2 diabetes. Diabetes Care 2009;32(2):S151-6. https://doi.org/10.2337/dc09S301

4. NICE. Preventing type 2 diabetes: risk identification and interventions for individuals at high risk. NICE Public Health Guidance. 2012. Available from: https://www.nice.org.uk/guidance/ph38/evidence

5. García-Pérez L, Alvarez M, Dilla T, Gil-Guillén V, Orozco-Beltrán D. Adherence to therapies in patients with type 2 diabetes. Diabetes Ther 2013;4(2):175-94. https://doi.org/10.1007/s13300-013-0034-y

6. Khunti K, Seidu S, Kunutsor S, Davies M. Association between adherence to pharmacotherapy and outcomes in type 2 diabetes: a meta-analysis. Diabetes Care 2017;40(11):1588-96. https://doi.org/10.2337/ dc161925 
7. Cramer J. A Systematic review of adherence with medications for diabetes. Diabetes Care 2004;27(5):1218-24. https://doi.org/10.2337/diacare.27.5.1218

8. Khunti S, Davies M, Khunti K. Clinical inertia in the management of type 2 diabetes mellitus: a focused literature review. Br J Diabetes Vasc Dis 2015;15(2):65-9. https://doi.org/10.15277/bjdvd.2015.019

9. Aronson J. Compliance, concordance, adherence. Br J Clin Pharmacol 2007:63(4):383-4. https://doi.org/10.1111/j.1365-2125.2007.02893.x

10. Cramer J, Roy A, Burrell A, et al. Medication compliance and persistence: terminology and definitions. Value Health 2008;11(1):44-7. https://doi.org/10.1111/j.1524-4733.2007.00213.x

11. Horne R, Weinman J, Barber N, Elliott R, Morgan M. Concordance, adherence and compliance in medicine taking. A Report for the National Co-ordinating Centre for NHS Service Delivery and Organisation R\&D. London, 2005. Available from: http://www.netscc.ac.uk/hsdr/files/project/SDO_FR_08-1412-076_V01.pdf.

12. World Health Organization. Adherence to long-term therapies: evidence for action. Geneva: World Health Organization. 2003. Available at: http://apps.who.int/medicinedocs/pdf/s4883e/s4883e.pdf

13. Osterberg L, Blaschke T. Adherence to medication. N Engl J Med 2005; 353(5):487-97. https://doi.org/10.1056/NEJMra050100

14. Davies M, D'Alessio D, Fradkin J. Management of hyperglycemia in type 2 diabetes, 2018. A consensus report by the American Diabetes Association (ADA) and the European Association for the Study of Diabetes (EASD). Diabetes Care 2018:41(12):2669-701. https://doi.org/10.2337/ dci18-0033

15. Praet $\mathrm{S}$, van Loon L. Exercise therapy in type 2 diabetes. Acta Diabetol 2009;46(4):263-78. https://doi.org/10.1007/s00592-009-0129-0

16. Rozenfeld Y, Hunt J, Plauschinat C, Wong K. Oral antidiabetic medication adherence and glycemic control in managed care. Am J Manag Care 2008;14(2):71-5.

17. Karter A, Parker M, Moffet H, Ahmed A, Schmittdiel J, Selby J. New prescription medication gaps: a comprehensive measure of adherence to new prescriptions. Health Serv Res 2009;44(5 Pt 1):1640-61. https://doi.org/10.1111/j.1475-6773.2009.00989.x

18. Guillausseau P. Influence of oral antidiabetic drugs compliance on metabolic control in type 2 diabetes. A survey in general practice. Diabetes Metab 2003;29(1):79-81. https://doi.org/10.1016/s12623636(07)70011-3

19. Ciechanowski P, Katon W, Russo J. Depression and diabetes: impact of depressive symptoms on adherence, function, and costs. Arch Intern Med 2000;160(21):3278-85. https://doi.org/10.1001/ archinte.160.21.3278

20. Dezii C, Kawabata H, Tran M. Effects of once-daily and twice-daily dosing on adherence with prescribed glipizide oral therapy for type 2 diabetes. South Med J 2002;95(1):68-71.

21. Donnan P, MacDonald T, Morris A. Adherence to prescribed oral hypoglycaemic medication in a population of patients with type 2 diabetes: a retrospective cohort study. Diabet Med 2002;19(4):279-84.

22. Donnelly L, Morris A, Evans J. Adherence to insulin and its association with glycaemic control in patients with type 2 diabetes. QJM 2007;100(6):345-50. https://doi.org/10.1093/qjmed/hcm031

23. Tiv M, Viel J, Mauny F, et al. Medication adherence in type 2 diabetes: the ENTRED study 2007, a French population-based study. PLoS One 2012;7(3):e32412. https://doi.org/10.1371/journal.pone.0032412

24. Davies M, Gagliardino J, Gray L, Khunti K, Mohan V, Hughes R. Realworld factors affecting adherence to insulin therapy in patients with type 1 or type 2 diabetes mellitus: a systematic review. Diabet Med 2013;30(5):512-24. https://doi.org/10.1111/dme.12128

25. American Diabetes Association. Pharmacologic approaches to glycaemic treatment: standards of medical care in diabetes-2018. Diabetes Care 2018:41(1):S73-85. https://doi.org/10.2337/dc18-S008

26. Russell-Jones D, Pouwer F, Khunti K. Identification of barriers to insulin therapy and approaches to overcoming them. Diabetes Obes Metab 2018;20(3):488-96. https://doi.org/10.1111/dom.13132

27. Gadkari A, McHorney C. Medication nonfulfillment rates and reasons: narrative systematic review. Curr Med Res Opin 2010;26(3):683-705. https://doi.org/10.1185/03007990903550586

28. Farmer A, Kinmonth A, Sutton S. Measuring beliefs about taking hypoglycaemic medication among people with type 2 diabetes. Diabet Med 2006;23(3):265-70.
29. Karter A, Subramanian U, Saha C, et al. Barriers to insulin initiation: the translating research into action for diabetes insulin starts project. Diabetes Care 2010;33(4):733-5. https://doi.org/10.2337/dc09-1184

30. Larkin M, Capasso V, Chen C, et al. Measuring psychological insulin resistance: barriers to insulin use. Diabetes Educ 2008;34(3):511-17. https://doi.org/10.1177/0145721708317869

31. Brundisini F, Vanstone M, Hulan D, DeJean D, Giacomini M. Type 2 diabetes patients' and providers' differing perspectives on medication nonadherence: a qualitative meta-synthesis. BMC Health Serv Res 2015; 15(1):516. https://doi.org/10.1186/s12913-015-1174-8

32. Claxton A, Cramer J, Pierce C. A systematic review of the associations between dose regimens and medication compliance. Clin Ther 2001; 23(8):1296-310. https://doi.org/10.1016/s0149-2918(01)80109-0

33. Pollack M, Purayidathil F, Bolge S, Williams S. Patient-reported tolerability issues with oral antidiabetic agents: associations with adherence; treatment satisfaction and health-related quality of life. Diabetes Res Clin Pract 2010;87(2):204-10. https://doi.org/10.1016/ j.diabres.2009.11.023

34. Hauber A, Mohamed A, Johnson F, Falvey H. Treatment preferences and medication adherence of people with type 2 diabetes using oral glucose-lowering agents. Diabet Med 2009;26(4):416-24. https://doi.org/ 10.1111/j.1464-5491.2009.02696.x

35. Walz L, Pettersson B, Rosenqvist U, Deleskog A, Journath G, Wändell P. Impact of symptomatic hypoglycemia on medication adherence, patient satisfaction with treatment, and glycemic control in patients with type 2 diabetes. Patient Prefer Adherence 2014;8:593-601. https://doi.org/ 10.2147/PPA.S58781

36. Bron M, Marynchenko M, Yang $H$, Yu A, Wu E. Hypoglycemia, treatment discontinuation, and costs in patients with type 2 diabetes mellitus on oral antidiabetic drugs. Postgrad Med 2012;124(1):124-32. https://doi.org/10.3810/pgm.2012.01.2525

37. McGovern A, Tippu Z, Hinton W, Munro N, Whyte M, de Lusignan S Comparison of medication adherence and persistence in type 2 diabetes: a systematic review and meta-analysis. Diabetes Obes Metab 2018;20(4):1040-3. https://doi.org/10.1111/dom.13160

38. McGovern A, Hinton W, Calderara S, Munro N, Whyte M, de Lusignan S. A class comparison of medication persistence in people with type 2 diabetes: a retrospective observational study. Diabetes Ther 2018;9(1):229-42. https://doi.org/10.1007/s13300-017-0361-5

39. Ho P, Rumsfeld J, Masoudi F, et al. Effect of medication nonadherence on hospitalization and mortality among patients with diabetes mellitus. Arch Intern Med 2006;166(17):1836-41.

40. Curtis S, Boye K, Lage M, Garcia-Perez L. Medication adherence and improved outcomes among patients with type 2 diabetes. Am J Manag Care 2017;23(7):e208-e214.

41. Wu Y, Yao X, Vespasiani $G$, et al. Mobile app-based interventions to support diabetes self-management: a systematic review of randomized controlled trials to identify functions associated with glycemic efficacy. JMIR Mhealth Uhealth 2017;5(3):e35. https://doi.org/10.2196/ mhealth.6522

42. Zafar A, Stone MA, Davies M, Khunti K. Acknowledging and allocating responsibility for clinical inertia in the management of type 2 diabetes in primary care: a qualitative study. Diabet Med 2015;32(3):407-13. https://doi.org/10.1111/dme.12592

43. Omran D, Guirguis L, Simpson S. Systematic review of pharmacist interventions to improve adherence to oral antidiabetic medications in people with type 2 diabetes. Can J Diabetes 2012;36(5):292-9. https://doi.org/10.1016/j.jcjd.2012.07.002

44. Schoenthaler A, Cuffee $Y$. A systematic review of interventions to. improve adherence to diabetes medications within the patientpractitioner interaction. J Clin Outcomes Manage 2013:20(11):494-506. http://www.mdlinx.com/hospital-administration/news-article.cfm/4949321/

45. Williams J, Walker R, Smalls B, Campbell J, Egede L. Effective interventions to improve medication adherence in type 2 diabetes: a systematic review. Diabetes Manag 2014;4(1):29-48. https://doi.org/10.2217/ dmt.13.62

46. Sapkota S, Brien JA, Greenfield J, Aslani P. A systematic review of interventions addressing adherence to anti-diabetic medications in patients with type 2 diabetes - impact on adherence. PLoS One 2015;10(2): 


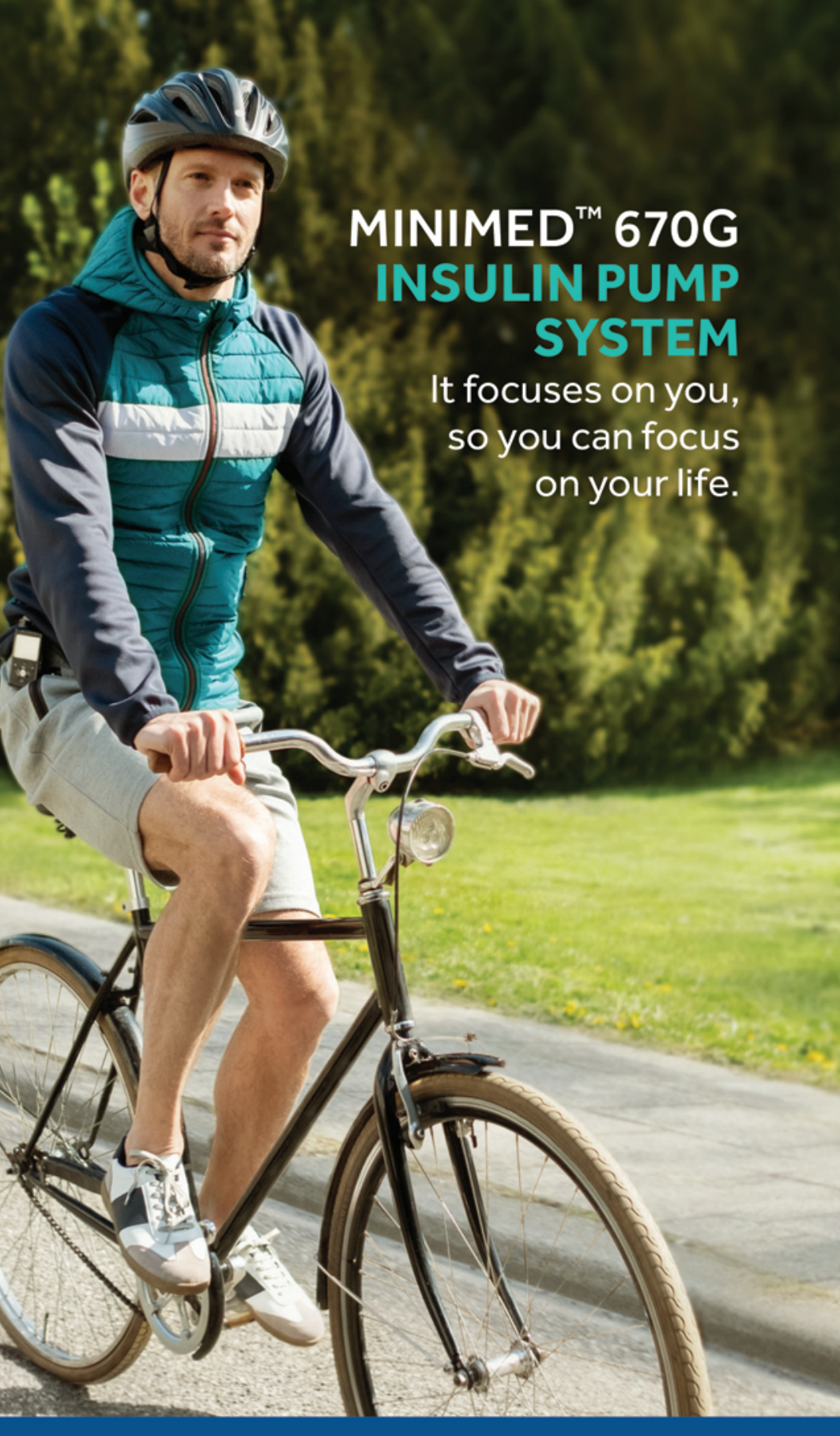

The MiniMed ${ }^{T M}$ 670G insulin pump system monitors your glucose values day and night and automatically adjusts basal insulin delivery to your needs to help stabilise your glucose levels with fewer highs and lows ${ }^{1,2}$.

Some user interaction is required.

References: 1. Bergenstal, R. M. et al. Jama. 2016; 316 (13): 1407 - 1408;

2. Garg SK et al. Diabetes Technol Ther. 2017 Mar;19(3):155-163

United Kingdom

Medtronic Limited

Building 9, Croxley Park

Hatters Lane.

Watford, Herts WD18 8WW

Diabetes Helpline: +44 (0)1923 205167 Diabetes Helpline: +353 (0)15111499 www.medtronic-diabetes.co.uk
Medtronic Ireland Limited Block 3090-3094,

Lake Drive

Citywest Business Campus, Dublin, DN24 XN47 www.medtronic-diabetes.ie

e0118296. https://doi.org/10.1371/journal.pone.0118296

47. Farmer A, Mcsharry J, Rowbotham S, McGowan L, RicciCabello I, French D. Effects of interventions promoting monitoring of medication use and brief messaging on medication adherence for people with type 2 diabetes: a systematic review of randomized trials. Diabet Med 2016;33(5):565-79. https://doi.org/10.1111/dme.12987

48. van Eikenhorst $L$, Taxis $K$, van Dijk L, de Gier H. Pharmacistled self-management interventions to improve diabetes outcomes. A systematic literature review and meta-analysis. Front Pharmacol 2017;8:891. https://doi.org/10.3389/ fphar.2017.00891

49. Jeong $\mathrm{S}$, Lee $\mathrm{M}$, Ji E. Effect of pharmaceutical care interventions on glycemic control in patients with diabetes: a systematic review and meta-analysis. Ther Clin Risk Manage 2018;14:1813-29. https://doi.org/ 10.2147/TCRM.S169748

50. Kebede M, Zeeb H, Peters M, Heise T, Pischke C. Effectiveness of digital interventions for improving glycemic control in persons with poorly controlled type 2 diabetes: a systematic review, meta-analysis, and meta-regression analysis. Diabetes Technol Ther 2018:20(11):767-82. https://doi.org/10.1089/ dia.2018.0216 